\title{
Conversational heuristics for eliciting shared understanding $\dagger$
}

\author{
MildRed L. G. SHAw \\ Middlesex Polytechnic Faculty of Education, U.K.
}

(Received 6 January 1979)

\begin{abstract}
A conversational method is necessary for experimenter and subject to collaborate in the exploration of the world of human beings. Individuals cannot be treated as objects, or be instructed how to take part in an experiment, without the recognition of the autonomy of each person and the invitation to participate jointly in co-operative exploration of the nature of man. An individual can be seen as a personal scientist who forms theories about the world and tests these theories against his personal experience of reality, adapting his theories for a more effective anticipation of events and hence a more competent interaction with his environment.

A suite of computer programs (PEGASUS, FOCUS, MINUS, CORE, ARGUS and SOCIOGRIDS) has been developed, each one acting as a cybernetic tool to enhance man's capabilities to understand both himself and his relationships with other perspectives of the world. PEGASUS is described, including PEGASUS-BANK which can be used to explore the relationship of an individual with another individual (or group). The CORE program can be used to chart change in a person over time, and to find the level of understanding and agreement between two people. Shared understanding within small groups can be investigated using the SOCIOGRIDS program which produces a mapping of the intra-group relationships, and the subject content which shows the extent of agreement in the group.

A study involving the exchange of subjective standards in human judgement is briefly described, and an analogy drawn to the understanding of different perspectives in the treatment of a medical or clinical patient.
\end{abstract}

\section{Conversational models}

A physical science paradigm is not necessarily helpful in dealing with people as subject matter. "Experiments" cannot be conducted on the assumption that either the subject or the experimenter remains unchanged as a result of the interaction. When a physical scientist sets up his experimental conditions he does so in such a way as to stabilize his observations which can then be repeated; that is, measured by other scientists looking from the same point and with the same perspective. The social scientist, however, is unable to keep his subject matter constant in quite the same way. There can no longer be an external observer but only participants helping each other. Therefore interaction between entities able to model themselves and others must necessarily take the form of conversation. Many people have recognized the need for personal involvement in learning, motivation and creativity, notably Rogers' (1969) learning contract, Kelly's (1962) and Maslow's (1954) ideas of motivation, and Kierkegaard's (1941) process of man "becoming his potentialities".

† This is partly based on a paper presented to the Twenty-Third Annual North American Meeting of the Society for General Systems Research at Houston, Texas, January 1979. 
Several models of conversation are useful in this context. Jahoda \& Thomas (1965) have developed a "science of learning conversations" in which the learning experience is viewed from different perspectives.

\begin{tabular}{|c|cc|}
\hline Purpose & Learner & Teacher \\
\hline Prospective & 1 & 2 \\
Retrospective & 3 & 4 \\
\hline
\end{tabular}

FIG. 1. The science of learning conversations.

Each of the four quadrants represents a different and valid point of view; quadrant 1 represents the learner's anticipation of the event; quadrant 2 represents the teacher's objectives; whereas quadrants 3 and 4 denote a retrospective view of the experience from the perspectives of the learner and the teacher respectively.

Luft's "Johari Window" (1961) is a model of interpersonal awareness which demonstrates the interaction of the two variables known/not known to self and known/not known to others, elaborated by Hanson (1973) in Fig. 2.

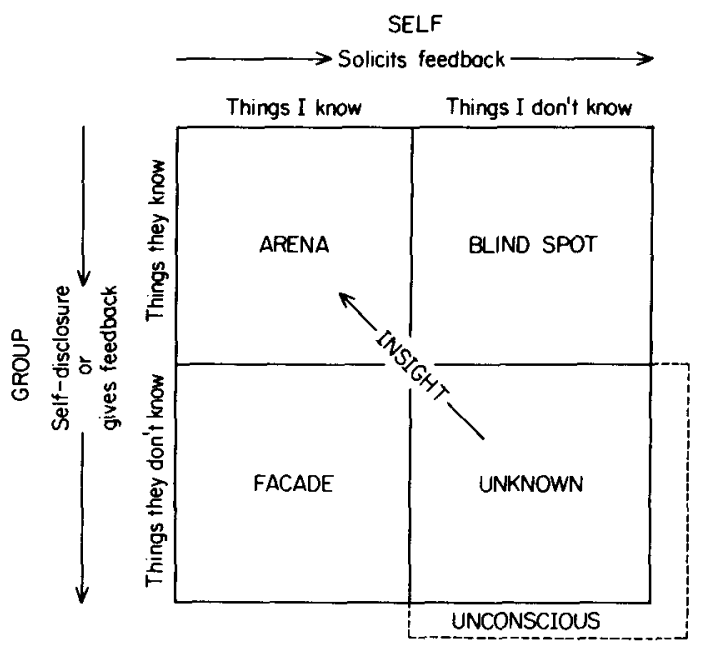

FIG. 2. The Johari Window.

The "arena" is characterized by free and open exchange of information and has an area proportional to the level of trust between the individual and the group. The "blind spot" contains information of which the individual is not aware but may have been communicated to the group by verbal or non-verbal cues. Quadrant 3 is the "facade" which contains information hidden from the group by the individual; and quadrant 4 represents information "unknown" to either the individual or the group.

Pask's (1975) "theory of conversations and individuals" suggests that participants in a conversation cannot be regarded simply as distinct processors, but he distinguishes a "mechanically characterized (M) individual" as a biologically self-replicating system 
and a "psychologically characterized $(P)$ individual" as a procedure executed in some processor. These P-Individuals are then similar in some ways to roles, perspectives, or points of view existing within and among the former M-Individuals. There may be several P-Individuals in one head as in a conversational private thinking or problemsolving activity, or one P-Individual constituting a conversation in a group. Each of these conversational models contributes to the ways in which a person can become a self-organized learner, able to act effectively in changing himself and his situation to be more viable in the world.

\section{The personal scientist}

For many years psychologists and others have been interested in how a person categorizes his experiences and classifies his environment. If the individual can become aware of how he is achieving this organization, he can not only use this awareness to predict more accurately and hence act more effectively, but also to change his system to adapt to specific needs of himself and others. Kelly's (1955) theory of a personal scientist was that each individual is seeking to predict and control events by forming theories, testing hypotheses and weighing experimental evidence. He suggests that the differences between the personal viewpoints of individuals may correspond to the differences between the theoretical viewpoints of scientists.

Each personal scientist uses himself as participative subject matter and construes and interprets the results in a personally meaningful way. To do this effectively a conversational method is used which is adapted from the repertory grid (Kelly, 1955). This is used as a tool together with the computer to enable an individual to examine and bring into awareness his own conceptual system. This technique assumes that each person can express his conceptual structure as a unique system of bipolar dimensions known as personal constructs through which he experiences life, and categorizes his experiences. This system of constructs acts like a pair of spectacles, focusing and colouring his external and internal worlds, and explains how similar events can produce quite different behaviour in different people.

\section{The repertory grid}

The repertory grid is a schema or two-dimensional array of events or observations and abstractions so interlaced as to enable each to have meaning in the context of the other. It is a finite system of cross-references between personal observations an individual has made and the personal constructs he has erected to make sense of his experiences. A set of constructs can be thought of as representing a P-Individual as it is a personal model of a topic emphasizing how a person thinks and feels about the topic in his own terms. These personal observations are known as elements and are chosen from the set of all observations to be relevant to the purpose for exploring this aspect of the individual's own phenomenological world. The elements then might be people, objects, events or ideas such as work colleagues or patients, books or symptoms, events or experiences in a course of treatment, aspects of self or possible careers. Care must be taken to ensure that each of the elements is well known and personally meaningful to the individual; and each construct is important to the individual in the context of the particular problem. Thoughts and feelings, objective and subjective descriptions, attitudes and prejudices 
all constitute valid constructs. The labels given to the constructs merely serve to remind the participants of the conversation. As an example think of the three learning activities of reading, writing and thinking. In what way are two of these alike and thereby different from the third?

Mr. A says: "Reading and writing are more alike because they are organized activities whereas thinking is haphazard."

Miss B says: "Writing and thinking are more alike because they concern only oneself whereas reading involves ideas from someone else."

Mrs. C says: "Reading and thinking are more alike because they are fun and interesting whereas writing is hard work."

Clearly each person has a different opinion and a different value system. Each of these dimensions is a personal construct because it is expressed in personally meaningful terms, and is significant to the person who used it. As each construct is elicited all the elements are assigned to one pole or the other. In the above example Mr. A's construct became:

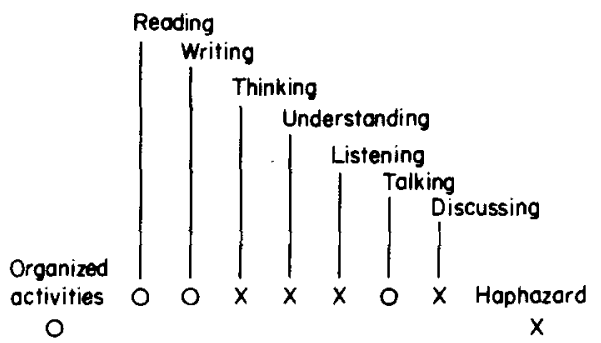

To elicit such constructs is a skilled activity. The eliciter must be careful not to contribute parts of his own construct system nor to distort in any way the constructs which are offered by the subject.

\section{PEGASUS}

In order to carry out a systematic elicitation process the computer program PEGASUS was developed (Shaw \& Thomas, 1978). This program, however, goes beyond the normal clinical method of grid elicitation and also provides an on-going analysis of the links being made between constructs and between elements.

Educationalists, therapists and trainers who use grid techniques will see this program as a useful grid elicitation package which extends the use and application of the grid by using the real-time data processing of the computer to provide feedback during the elicitation, and the analysis of the results immediately on completion. Although this "grid-centred" point of view construes the program as convenient and systematic, it misses the full potential of the "learning-centred" approach of the cognitive model. A personal scientist models reality in order to anticipate events, and the quality of a person's models undoubtedly determines the level of competence and creativity he is able to achieve. There is considerable potential in programs such as PEGASUS to enable a person to become aware of his models, and revise them in order to increase his 
capacity for anticipation. Awareness raising cannot be measured by the level of achievement of behavioural objectives, but rather it is a change in the personal construing of the individual and the revision of his cognitive model. This "learning centred" approach has recommended PEGASUS to teachers and trainers, industrial inspectors and maintenance engineers, managers and appraisers, in addition to researchers and psychotherapists.

Another version of the program is PEGASUS-BANK. This allows a grid to be stored in the computer representing an area of public knowledge. The user elicits a grid in the usual PEGASUS way, but the feedback is given not only in terms of how the user's constructs map onto each other, but how they map onto the "expert" view. This can also be used to initiate a user into the views and culture of a group, and help him to understand the words and terms used by the experts. This technique, therefore, offers a useful starting point for assessment and training. Although the analysis and the feedback of the results is central to the elicitation, the process of the PEGASUS procedure is both stimulating and demanding. The computer acts as a cognitive mirror in which the user sees himself, and with PEGASUS-BANK the world external to himself.

\section{Shared understanding}

The PEGASUS-BANK technique of storing in the computer a bank of constructs which represents an area of public knowledge or the construing of a group of specialists, shows how an individual can use the grid methodology to interface between his early gropings and the articulate formulations of the group. It can also be used for two people to come to an understanding of each other. One may elicit a grid which is stored in the computer for the other to use as he elicits his own grid using the same elements. At each stage the bank may be increased or modified hence encouraging each of the two participants to take on the construct system of the other by mapping out the similarities between the patterning, and hence meanings can be exchanged between the pair. Alternatively, if each elicits a grid independently, using a shared set of elements, the two grids may be compared by matching the patterning of the responses.

Whether or not the grids have been elicited on separate occasions, if the element and construct labels are the same in both grids they can be compared with respect to the similar or different uses of these names by examining the differences in the patterning in each grid. MINUS is a program which identifies the difference and similarity between the two grids by superimposing one on the other. The resulting matrix is then focused to identify those constructs and elements which are being used in the same way. A measure of overlap is produced based on the matching scores algorithm which is given as a percentage of the possible similarity in the two patterns of responses (see Shaw \& Thomas (1978)).

An important property of a construct is its treatment of the elements of construction. If two constructs have been used in relation to the same element set, then the way they act on the elements may be compared. If the same person elicits two grids with the same element and construct names on two separate occasions, which are then processed on MINUS, it is possible to see the elements and constructs which have remained the same in meaning, and those which have changed in some respect. One may assume that those constructs less liable to fluctuation over short periods of time in which no excessive 
physical or emotional upheaval has taken place are likely to be core constructs; that is, those which govern a person's maintenance processes, as opposed to those which can be changed without seriously affecting the core structure. If the same constructs persist over a series of grids this becomes even more likely.

\section{The CORE program}

A more flexible approach to identifying core constructs is developed in the CORE program. In order to measure change in the two dimensions of elements and constructs, each is held constant alternately whilst change in the other is calculated. The two grids have the same element and construct names, therefore one assumes, say, the constructs are the same and examines the clustering of the elements when the two grids are analysed as one using part of the FOCUS algorithm:

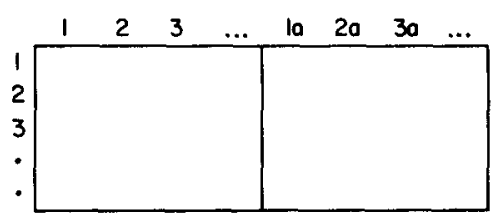

If in fact element 1 and element $1 \mathrm{a}$ (that is element 1 in the second grid) are being construed in the same way they will be highly matched in the double grid. If then the two grids are processed by keeping the elements constant and allowing the constructs to vary, similarly, the constructs operating on the elements in the same way on both occasions will cluster together:

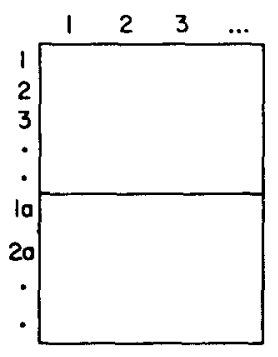

By alternating in this way no assumption is made about the stability of any element or construct.

If the user is more interested in constructs and does not wish to delete elements, or vice versa, the program allows just constructs to be deleted until the decision is made to stop. Flexibility is thereby given to the person who most understands the content of the grid to use his subjective judgement, rather than taking a statistically significant but nevertheless arbitrary cut-off point. If the user continues until all match values are $100 \%$, then the two partial grids which remain will be identical and as such may be designated "the core grid". 


\section{Exchange grids}

Agreement and understanding can each be negotiated in a similar way using the CORE procedure. To do this two people each elicit a grid in an area of common knowledge or experience. Each may choose his own elements independently of the other and elicit and rate his constructs quite separately. Each then makes two copies of his grid leaving out the rating values. Each of these copies is filled in by the other person, one as he himself uses those constructs on those elements and the other as he thinks the original was completed. There are now six grids:

(1) A's grid;

(2) B's grid;

(3) A's grid filled in by B as B wants it filled;

(4) B's grid filled in by A as A wants it filled;

(5) A's grid filled in by B as B thinks A did it;

(6) B's grid filled in by A as A thinks B did it.

These have been called "exchange grids" (Mendoza, 1970). If these are then processed in pairs on CORE: 1 and 3,2 and 4 represent agreement; 1 and 5, 2 and 6 represent understanding. The extent of the agreement and of the understanding will be indicated by the relative size of the core grid obtained, and the areas of disagreement and misunderstanding will be mapped out by those constructs and elements which are discarded at different levels of match during the process. This then opens up an area for conversation, and negotiation can take place securely grounded in the grid structure.

\section{SOCIOGRIDS}

Although CORE offers new potential for investigating understanding between two people, it is not always appropriate to use the same element and construct names. Kelly's position was that both elements and constructs should be elicited from the individual, but when neither elements nor constructs are common, measures of overlap are difficult to derive.

Elements are more easily shared than constructs, since they are representatives of the universe of discourse. If they are physical entities or shared experience, both participants are likely to be able to construe them without difficulty. Personal constructs are then elicited individually, resulting in two grids with the same elements but each with different constructs. These two grids can then be compared, the FOCUS algorithm providing a convenient method for this comparison. As the two grids have the same elements but different constructs they may be combined and treated as one grid, the first $n$ constructs being from person $\mathrm{A}$ and constructs $n+1, \ldots, N$ from person B. By matching each of the rating patterns of the constructs from grid $A$ in turn with each of the constructs in grid $\mathrm{B}, \mathrm{a}$ measure of the extent of similarity between the two grids can be established.

Kelly's commonality corollary states that: "to the extent that one person employs a construction of experience which is similar to that employed by another, his processes are psychologically similar to those of the other person." This does not imply that this similarity is necessarily the totality of his psychological processing. Imagine an extreme case. In construing a certain topic, person A habitually uses four constructs while person 
B habitually uses two. The constructs used by B are identical to two of A's constructs. Now, when in conversation about this topic, A may be able to empathize totally with $B$, as $B$ is using exactly the same construing as $A$, but $B$ may not be able to empathize with $A$ when $A$ is using those constructs not common to $B$. The measure of commonality used is sensitive to this situation; the mapping of grid A onto grid B produces a different degree of similarity from that of grid B onto grid A. Clearly if A and B are using constructs in the same way to order the elements then this will be revealed despite the verbal labels which have been attached to them. This technique can then be extended to investigate the commonality in a group by considering the overlap between every possible pair of grids. This is the basis of the SOCIOGRIDS program.

Each individual set of personal constructs represents that person's thoughts and feelings about the universe of discourse. As these are expressions of the person's construct system played out in this domain, ideas are tapped which the individual is bringing to bear on the subject perhaps without his own knowledge. If some of these ideas are shared by other members of the group, it may benefit all the participants to have them made explicit.

A "mode" grid of the most commonly used constructs by all the members of the group is extracted and focused, exhibiting the content of the shared construing in the group. Each construct in the mode grid has been obtained from one individual in the group and is in no way changed when used in the mode. This grid then is not a consensus grid which averages out the individualities to produce a pale imitation of the group, but is strongly weighted towards the commonality or intersection of construing within the group. Due to this format the constructs tend to be highly clustered in the mode grid, and generally these clusters display a high degree of both literal and conceptual similarity in the construct labels as denoted by Duck (1973). In a field where more technical language is used it would be impossible for the non-expert to rely on his own judgement of what constituted literal and conceptual similarity. This seems a powerful technique for identifying such similarity by a more reliable process than has been used in the past (see Thomas, McKnight \& Shaw, 1976). The mode grid can then be used as a common referent for the group with which each individual may be compared.

A sequence of sociometric diagrams designated "socionets" is produced from the matrix of similarity measures between pairs of individual grids. The highest related pair is picked out initially as a subgroup where commonality of construing occurs, followed by the subgroups defined by the rank ordering of all the similarity measures. This set of socionets shows those members of the group who have the most in common and those with strongly individualistic viewpoints. For example, in the treatment of a patient, the patient's problem may have quite different meanings for a harrassed nurse, a chief consultant, or a physiotherapist. The position, responsibilities and experience of each of these people will have led them to develop a different set of personal constructs and so each will construe the patient differently. The constructs which a person brings to a situation lead him to see that situation in a particular way. They lead him to select certain aspects and ignore others and they determine the way in which perceived dimensions are combined into an overall meaning. For example, the details which concern the nurse are unimportant to the consultant, and the physiotherapist might see that a particular treatment would be suitable for Mr A but not for Mrs B.

The grid techniques offer a means of discovering the terms in which these different people, all of whom have the same objective with respect to the patient, appreciate the 
problems involved. It can reveal the basic structure of values which forms the basis of human judgement, often only vaguely appreciated by the individual himself.

\section{Exchange of subjective standards}

A study was carried out recently into subjective standards in the inspection of knitwear (Pope, Shaw \& Thomas, 1977; Shaw, 1979). At first sight this is totally removed from medical and clinical practice, but on examination it can be seen to be an analogous situation. The purposes of the study were to help each manager, supervisor and inspector to become more aware of his or her own personal dimensions for judging faults in garments and to explore the pattern of judgements within the group in order to discuss the similarities and differences that exist between individuals. Four final inspectors from the production line out of a total of eight participated in the exercise together with the inspection supervisor, the production manageress, the production manager, the divisional manager and a trainee production technologist. Figure 3 shows the hierarchy within the organization of those involved.

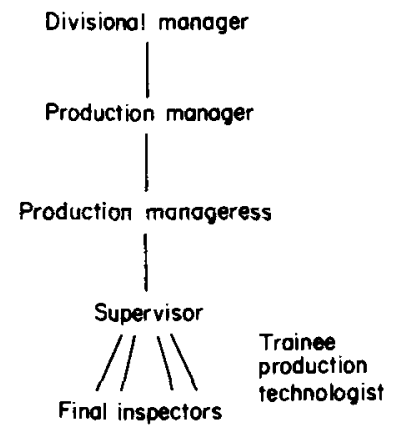

FIG. 3. The organizational structure.

Each member of this group was shown a range of garments currently in production and asked to describe the process of inspection and the faults which would specifically be looked for during the inspection procedure. As this was done, the faults mentioned were noted and subsequently used as elements in a grid. After each person had separately identified elements of quality and elicited a grid, the group, excluding the production manager and divisional manager, met together to examine the total list of elements produced, and negotiate a common set of elements which could be shared by them all. (The reason for the exclusion was partially practical in terms of time commitment, and partially to avoid inhibiting the less senior members of the organization.) Each person then elicited a new grid using the negotiated element set, and the constructs which had been personally produced on the previous occasion with the addition of one offered construct. The opportunity was given to add extra elements and constructs. The two grids from each person were then FOCUSed, and the second set analysed on SOCIOGRIDS. A number of other analyses were performed, including a clustering of the original element list from the verbal labels, and the extraction of a grid made up of the offered construct from each person. 
A week after the initial grids were elicited, each person was presented with his/her personal results, and the group results. During the feedback of the results, each person was encouraged to identify his/her position with respect to the other people in the group, both from the links made in the socionets and from the list of constructs ordered by common usage; also examining similarities and differences shown by the clustering of elements and constructs in the personal individual grids.

Following the individual feedback sessions, the four inspectors met to discuss the variety in the group. This led to the negotiation and exchange of meaning of the exact nature of the faults concerned.

Figure 4 shows a grid from the first set elicited from one of the final inspectors using her own elements. The elements used by people in other positions in the company varied somewhat, but all agreed on a common set of elements for the second set of grids.

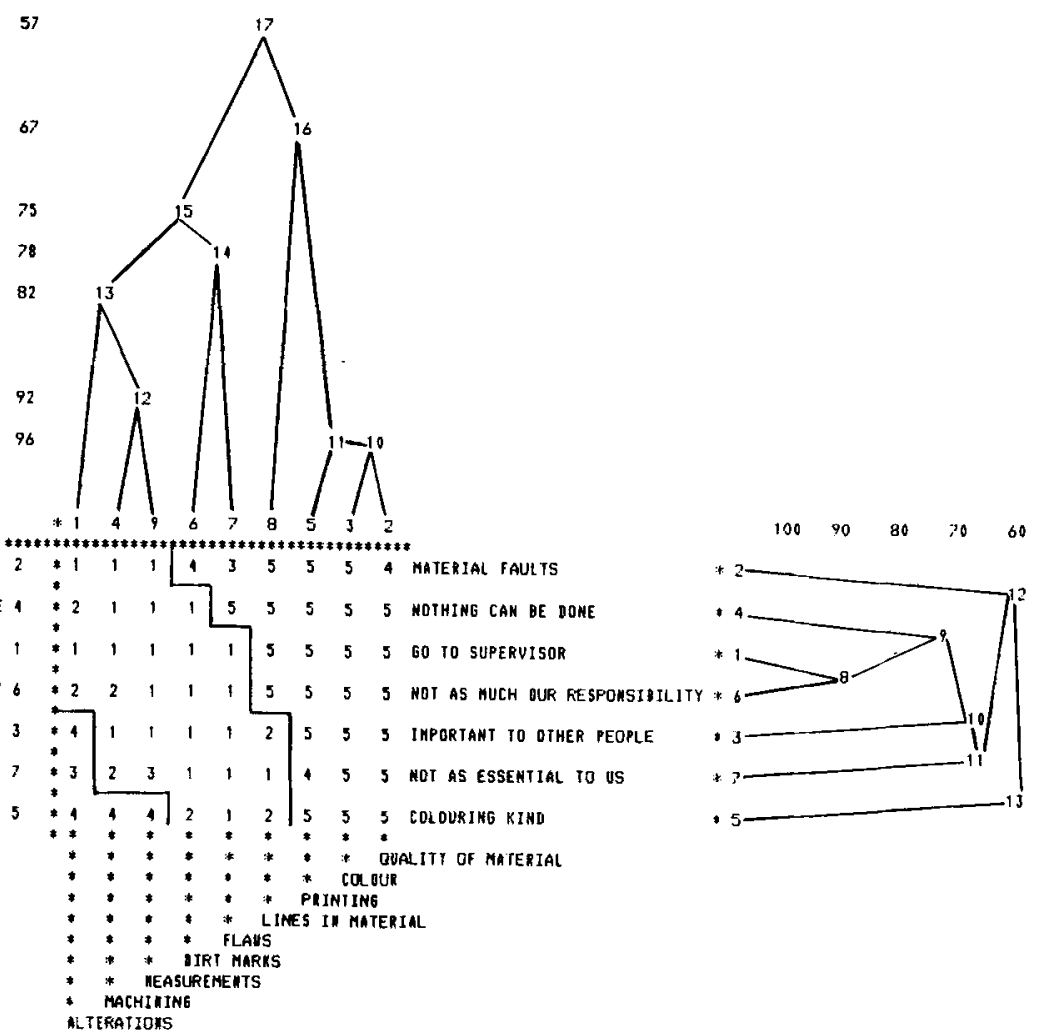

FIG. 4. A grid on faults in garments from the first set using a 5 point scale.

Figure 5 shows the mode grid made up of the eleven most shared constructs. Two of the inspectors and the divisional manager contributed nothing to this grid, whereas one of the inspectors contributed four constructs, and the production manager contributed three. The element clusters show the three faults "shading fault", "fabric fault" and "print fault" to be construed similarly on the left of the tree, and the three faults 


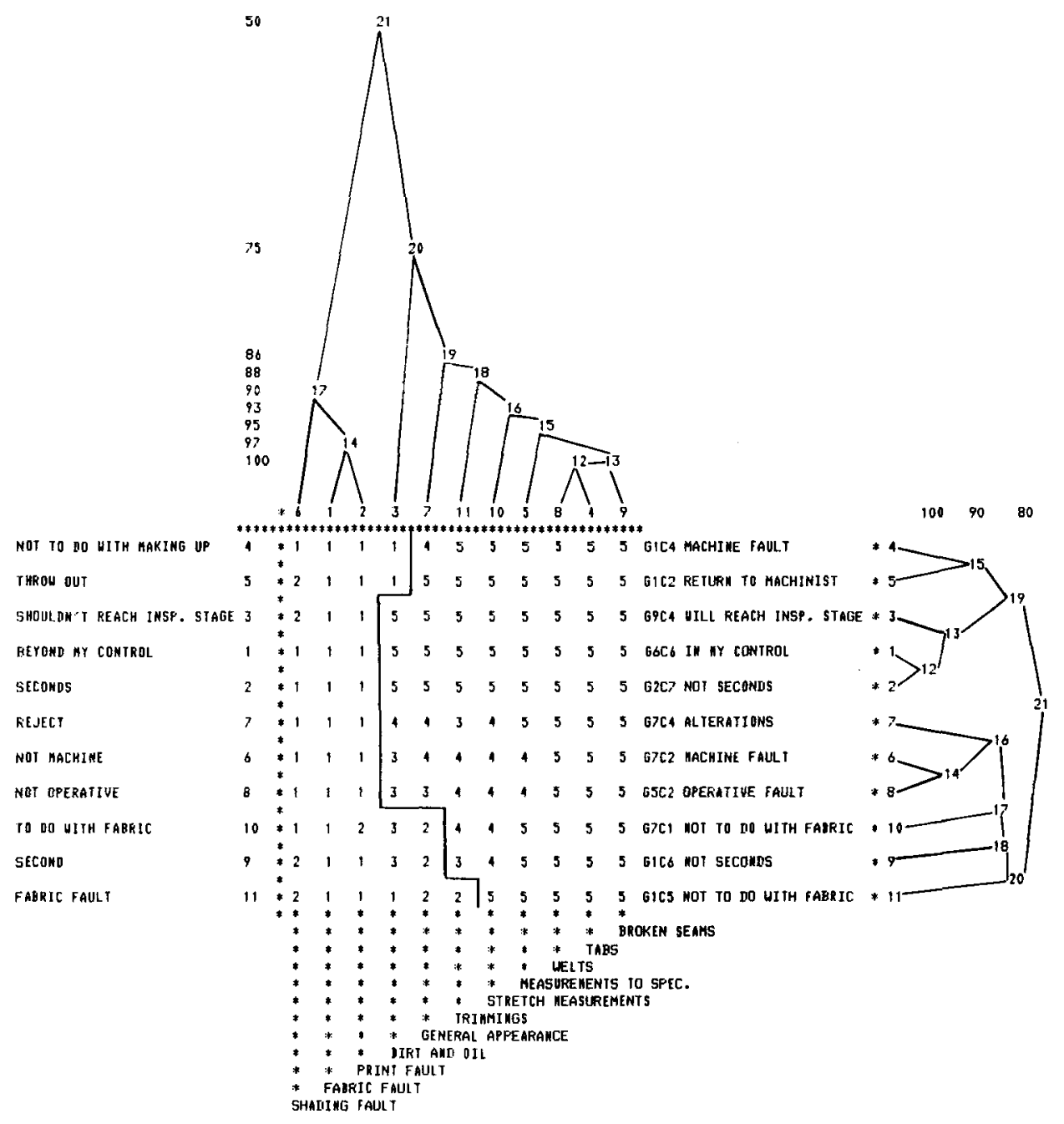

FIG. 5. The mode grid on faults in garments.

"broken seams", "tabs" and "welts" to be construed similarly on the right of the tree. This right-hand cluster then gradually incorporates each of the remaining faults one at a time, until "dirt and oil" enables it to join with the other cluster. It can be seen that "dirt and oil", "general appearance" and to some extent "trimmings" are viewed variably, not being clearly to one or other pole of all the constructs as the other faults are.

Since everyone was using the same set of elements, it was possible to extract the one offered construct "very important-not so important" from each grid. This is shown in Fig. 6. The construct tree now shows the relationship of the people who took part in this study with respect to the importance they attach to different faults in the garments. It is interesting to note that reading down from the top of the construct tree one is reading down the hierarchy within the group; 8 is the divisional manager, 7 is the production manager, 6 is the manageress, 5 is the supervisor, 1 to 4 are the inspectors and 9 is the 


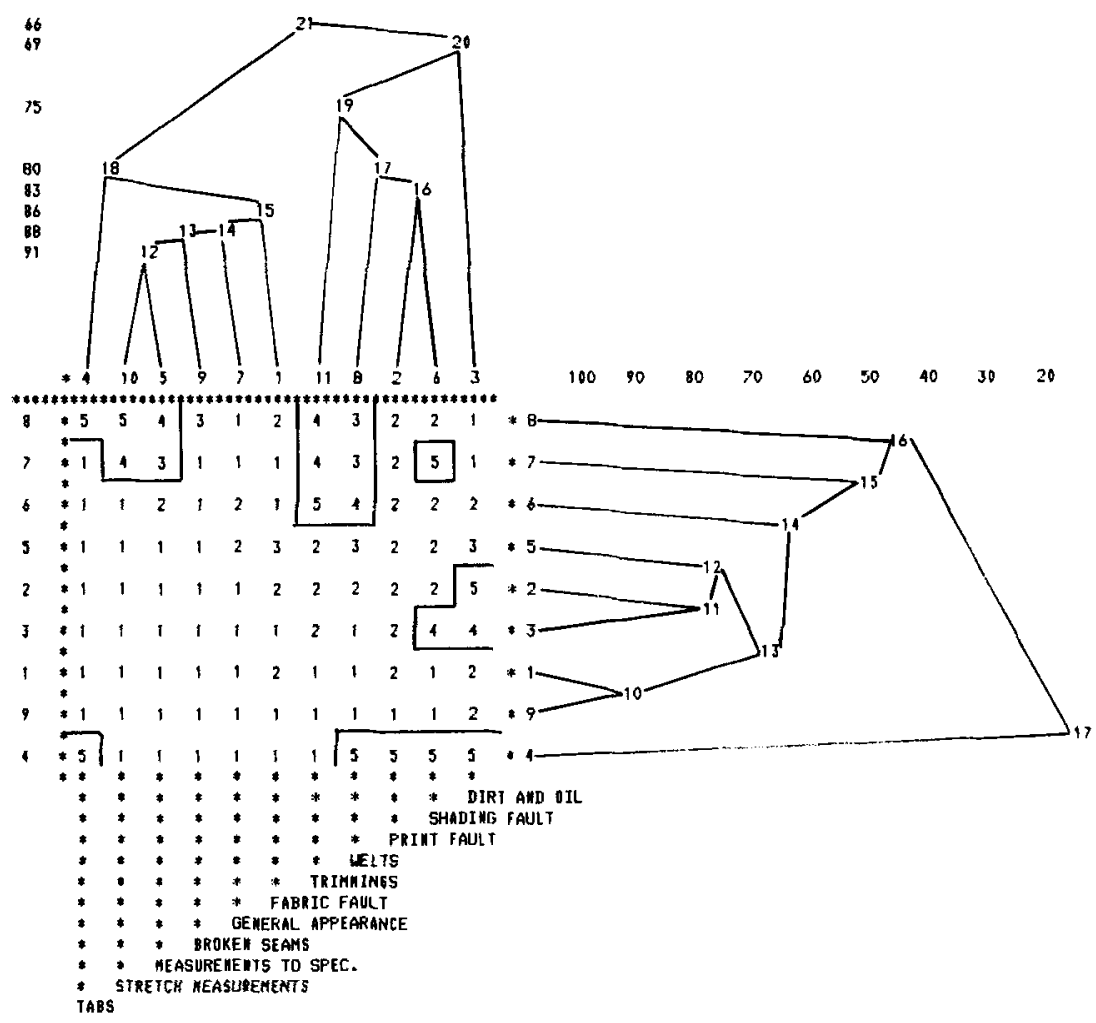

FiG. 6. The "offered construct" grid on faults in garments.

trainee. A possible explanation of the separateness of 4 is the difference in the use of the 1 to 5 scale. Whereas person 4 used the two poles 1 and 5 , most other inspectors used 1 and 2 to differentiate importance.

Figure 7 shows diagrammatically the system of connections between the participants (expressed as links to the three grids which were most like the person's own grid). Points of interest are:

(i) three inspectors and the trainee production technologist shared similar views of faults;

(ii) one of the inspectors seemed to differ from this group;

(iii) the supervisory and management group shared similar views of faults although the similarity is less strong and differs from that of the inspectors;

(iv) the patterns of reciprocal similarities, i.e. among inspector and trainee, between supervisor and production manager and divisional manager;

(v) each of the supervisory/management group relate to inspector 2.

The results show that different roles within the company incorporate different viewpoints of quality, and provide a foundation for the negotiation and exchange of meaning. This can help both the company and the individuals to realize each position and how it contributes to the whole. In the case of the patient also, a better understand- 


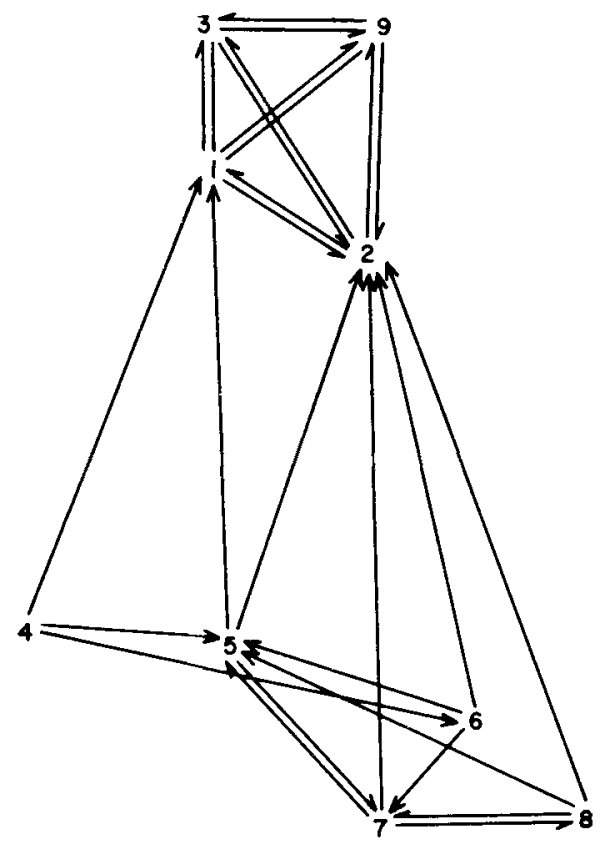

FIG. 7. Diagram showing the systems of connection between participants.

ing of each person's point of view, how he or she sees the links in the whole system, and awareness of effect of individual action within the system must contribute to a more viable working relationship, and hence benefit all concerned.

\section{Conclusion}

The grid is therefore a rigorous but flexible structure which is held by the computer whilst the system of constructs is elicited from the individual and processed in a participative way (Shaw, 1978). The personal scientist can use the grid together with the computer as a sensitive instrument to enhance his essentially human skill, not as a machine which removes the human part of the work and reduces man to a moronic button-pusher. Gaines (1977) goes even further by suggesting that the computer can become more like a colleague, expressing sympathy and understanding to the user.

With the decreasing cost of microprocessors, the personal computer will soon be commonly available to anyone. These grid techniques may then be incorporated as additional resources in the cybernetic toolbag to explore systems of personal meaning in a non-directive and supportive way, enabling the individual to build, review and revise his personal models of the world and hence predict and act more effectively.

\section{References}

DuCK, S. W. (1973). Personal Relationships and Personal Constructs-A Study of Friendship Formation. New York: John Wiley.

GAINES, B. R. (1977). Minicomputers in business applications in the next decade. Paper for Infotech State-of-Art Report on Minis Versus Mainframes. 
Hanson, P. C. (1973). The Johari Window: a model for soliciting and giving feedback. The 1973 Annual Handbook for Group Facilitators, pp. 114-119.

JAHODA, M. \& THOMAS, L. F. (1965). A search for optimal conditions of learning intellectually complex subject matter. 3rd Progress Report. Centre for the Study of Human Learning, Brunel University.

KELly, G. A. (1955). The Psychology of Personal Constructs. New York: W. W. Norton.

KELLY, G. A. (1962). Europe's matrix of decision. In JONES, M. R., Ed., Nebraska Symposium on Motivation. University of Nebraska Press.

KierkegaARD, S. (1941). Concluding Unscientific Postscript. Princeton University Press.

LuFT, J. (1961). The Johari Window. Hum. Rel. Train. News, 5, 6-7.

MASLOW, A. H. (1954). Motivation and Personality. New York: Harper and Row.

MENDOZA, S. (1970). Personal construction of the world and its control and development by the individual. Unpublished B. Tech. Project. Brunel University.

PASK, G. (1975). The Cybernetics of Human Learning and Performance. London: Hutchinson Educational.

POPE, M. L., Shaw, M. L. G. \& Thomas, L. F. (1977). A report on the use of repertory grid techniques in final inspection. Centre for the Study of Human Learning, Brunel University.

ROGERS, C. R. (1969). Freedom to Learn. Columbus, Ohio: Charles Merrill.

SHAW, M. L. G. (1978). Two roles for the computer in cognizant systems. Paper read to Fourth European Meeting on Cybernetics and Systems Research, Johannes Kepler University, Linz.

SHAW, M. L. G. (1979). On Becoming a Personal Scientist: Interactive Computer Elicitation of Personal Models of the World. London: Academic Press (in press).

SHAW, M. L. G. \& THOMAS, L. F. (1978). FOCUS on education-an interactive computer system for the development and analysis of repertory grids. International Journal of Man-Machine Studies, 10, 139-173.

Thomas, L. F., MCKNIGHT, C. \& SHAw, M. L. G. (1976). Grids and group structure. Paper presented to the Social Psychology Section of the B.P.S., University of Surrey. 